\title{
PROJETO DE ASSENTAMENTO CHE GUEVARA: UM ESTUDO PEDOLÓGICO VISANDO A CLASSIFICAÇÃO DA CAPACIDADE DE USO DA TERRA
}

\author{
Natália Aragão de Figueredo ${ }^{1}$ \\ João Luiz Lani ${ }^{2}$ \\ José Ambrósio Ferreira Neto ${ }^{1}$ \\ Marco Antônio Gomes ${ }^{3}$ \\ Roseni Aparecida de Moura ${ }^{1}$
}

\section{RESUMO}

Os Projetos de Assentamentos instituídos pelo Governo Federal foram criados como forma de solucionar injustiças sociais e conflitos ligados à posse de terras em todo o país. Porém, a criação desses projetos acarreta mudanças por envolver alterações nas formas de uso da terra,o que pode provocar alterações ambientais. O presente trabalho buscou identificar os componentes ambientais (solos, geologia e geomorfologia) e o uso da terra para assim classificar a capacidade de uso da terra no Projeto de Assentamento (PA) Ernesto Che Guevara de modo a subsidiar a tomada de decisão para um melhor planejamento dos recursos naturais. A fim de se alcançar os objetivos esperados foram realizadas três etapas metodológicas durante o estudo: trabalho de campo, análises laboratoriais e digitalização de informações por geoprocessamento. Desta forma, $84,8 \%$ das terras são passíveis de utilização com culturas anuais, perenes, pastagens e/ou reflorestamento e vida silvestre (Classe III); 11,38\% das terras são próprias para proteção da fauna e flora silvestre e $3,83 \%$ pertencem a Classe VII que são terras adaptadas somente para pastagens ou reflorestamento com problemas complexos de conservação. De forma geral, as terras do PA requerem medidas intensivas para utilização, com problemas relativos ao solo e susceptibilidade à erosão.

Palavras-chave: solos; uso das terras; assentamentos rurais.

${ }^{1}$ Departamento de Economia Rural, Universidade Federal de Viçosa

2 Departamento de Solos/Universidade Federal de Viçosa.

${ }^{3}$ Universidade Estadual de Minas Gerais 


\section{ABSTRACT}

The rural settlements were created by the Brazilian government as a way to solve the social inequity and conflicts related to the land ownership around the country. However, the creation of these projects has entailed changes because it involves alteration in the land use and may provoke environmental changes. This paper aimed at identifying the environmental components (soils, geology, geomorphology) and land use in order to classify the land use capacity in the "PA" Ernesto Che Guevara. The objective is to subsidize the decision taking to improve the natural resources planning. In order to achieve the expected goals three methodological steps were followed during the study: fieldwork, laboratory analysis and digitalization of information using geoprocessing. Thus, $84.8 \%$ of the land may be used for annual, perennial crops, pastures and / or reforestation and wildlife (Class III); $11.38 \%$ of the land are suitable for protection of wild fauna and flora and $3.83 \%$ belong to Class VII that are suitable only for grazing land or reforestation with complex conservation issues. In general, the PA lands require intensive measures for use, with problems related to ground and susceptibility to erosion.

Keywords: Soils. Land use. Rural settlements.

\section{INTRODUÇÃO}

A criação dos assentamentos rurais pode ser entendida como conjunto de medidas que visam promover a melhor distribuição da terra, mediante modificações no regime de sua posse e uso, a fim de atender ao princípio de justiça social, ao aumento de produtividade e ao cumprimento da função socioambiental da propriedade (INCRA, 2001). Pode-se dizer que os assentamentos são também resultado da histórica luta dos produtores rurais familiares, além de ser uma das soluções encontradas para os atuais problemas sociais e ambientais associados ao uso e ocupação do espaço. Porém, a criação e implementação desses projetos acarretam várias mudanças nas formas do uso da terra o que, por sua vez, pode ocasionar mudanças negativas tanto para os assentados como para o meio ambiente (LANI et al, 2010).

Nesse sentido, os Projetos de Assentamentos (PA's) criados pelo Governo Federal têm como objetivo solucionar injustiças sociais e graves conflitos ligados à posse de terras em todo o país. Entretanto, o Instituto Nacional de Colonização e Reforma Agrária (INCRA), responsável pela política de criação dos assentamentos rurais no país, tem sido apontado como um órgão fomentador da destruição de florestas primárias, uma vez que não faz um planejamento prévio para seus projetos, que são implantados a partir de parâmetros abstratos, que não consideram o potencial e a vulnerabilidade ambiental das áreas desapropriadas disponíveis, provocando com isso, modificações substanciais no uso da terra (WOLSTEIN, 1998).

Para evitar que essas externalidades negativas do processo de criação dos assentamentos rurais, que por vez comprometem o meio ambiente e a própria sustentabilidade desses projetos, é indispensável o conhecimento do uso dado ao solo nessas áreas.Assim, o levantamento e mapeamento das classes de solos e do uso atual da terra associada à avaliação da capacidade de uso das terras servem de base para o planejamento da ocupação antrópica das terras de forma racional, melhorando a produtividade agrícola e sustentabilidade dos projetos (LEPSCH et al, 1991).

Neste contexto, o presente trabalho realizou o levantamento dos solos, das classes de relevo eo uso da terra sobdiferentes parâmetros para classificar a capacidade de uso das terras e, assim,fornecer dados que possibilitam subsidiar a tomada de decisão para um melhor uso dos recursos naturais no Projeto de Assentamento Ernesto Che Guevara, de modo a proporcionar conhecimento do uso dos solos e melhores alternativas de manejo para as famílias assentadas. 


\section{MATERIAL E MÉTODOS}

\section{Área de estudo}

O PA Ernesto Che Guevara localiza-se no município de Mimoso do Sul, microrregião de Cachoeiro de Itapemirim a qual se encontra inserida, numa escala estadual, na Mesorregião Sul Espírito-santense. Foi criado em 22 de abril de 2004 e possui uma área total de 463,7952 hectares e perímetro de $9.555 \mathrm{~m}$.

\section{METODOLOGIA}

A metodologia consistiu no levantamento das principais classes de solos, uso da terra, aspectos climáticos, geológicos e geomorfológicos além do levantamento produtivo do assentamento. Para mapeamento e caracterização foi realizado trabalho de campo e selecionadas as principais classes de solos, uso do solo e áreas degradadas. Após esta caracterização e seleção, foram abertos nove perfis representativos para proceder à descrição morfológica do perfil e coleta de amostras de cada horizonte.

Posteriormente, as amostras coletadas foram secas aoar, tamisadas em peneiras com malhas de $2 \mathrm{~mm}$ (ABNT-10) obtendo-se assim afração terra fina seca ao ar (TFSA) na qual procederam-se às análises físicas e químicas. A análise granulométrica para separação das frações argila, silte e areia foi utilizada seguindo os parâmetros: a fração argila foi determinada pelo método da pipeta e a fração silte por diferença. Após contato das amostras de $10 \mathrm{~g}$ de TFSA com a solução de $\mathrm{NaOH} 0,1 \mathrm{~mol} \mathrm{~L}^{-1}$ por 12 horas e, posteriormente, agitadas em rotação de $50 \mathrm{rpm}$ por 16 horas. A fração areia grossa foi separada por peneira de malha de $0,2 \mathrm{~mm}$ e, a fração areia fina por peneira de malha $0,053 \mathrm{~mm}$.

Foram realizadas também análises químicas para identificar os principais elementos químicos como:cálcio, magnésio e alumínio trocáveis extraídos em solução $\mathrm{KCl} 1 \mathrm{~mol} \mathrm{~L}^{-1}$ e determinados por titulação; potássio e sódio extraídos com solução de Melich $^{-1}$ e determinados por fotometria (Embrapa, 2006); fósforo disponível extraído com solução de Melich ${ }^{-1}$ e determinação por colorimetria; $\mathrm{pH}$ (em água e em solução de $\left.\mathrm{KCl} 1 \mathrm{~mol} \mathrm{~L}^{-1}\right)$. O carbono orgânico foi determinado pelo processo de Walkley\& Black de acordo com Defelipo\& Ribeiro (1997). O alumínio trocável foi extraído com $\mathrm{KCl} 1 \mathrm{~mol} \mathrm{~L}^{-1}$, na proporção 1:10, e determinado por titulação com NaOH 0,025 mol L-1 (DEFELIPO e RIBEIRO, 1997). A acidez potencial $\left(\mathrm{H}^{+}+\mathrm{Al}^{3+}\right)$ extraída com acetato de cálcio $0,5 \mathrm{~mol} \mathrm{~L}^{-1}$, na relação $1: 15 \mathrm{com}$ pH ajustado a 7,0, e determinada por titulação com $\mathrm{NaOH} 0,025 \mathrm{~mol} \mathrm{~L}^{-1}$. Com base nos dados analíticos foram calculados os valores de Soma de Bases (SB), Capacidade de Troca de Cátions (T), Saturação por Bases (Valor S) e Saturação por Alumínio (m). A Figura 1 apresenta o organograma das atividades realizadas em campo e no laboratório. 
Figura 1. Organograma das atividades realizadas no campo e laboratório.

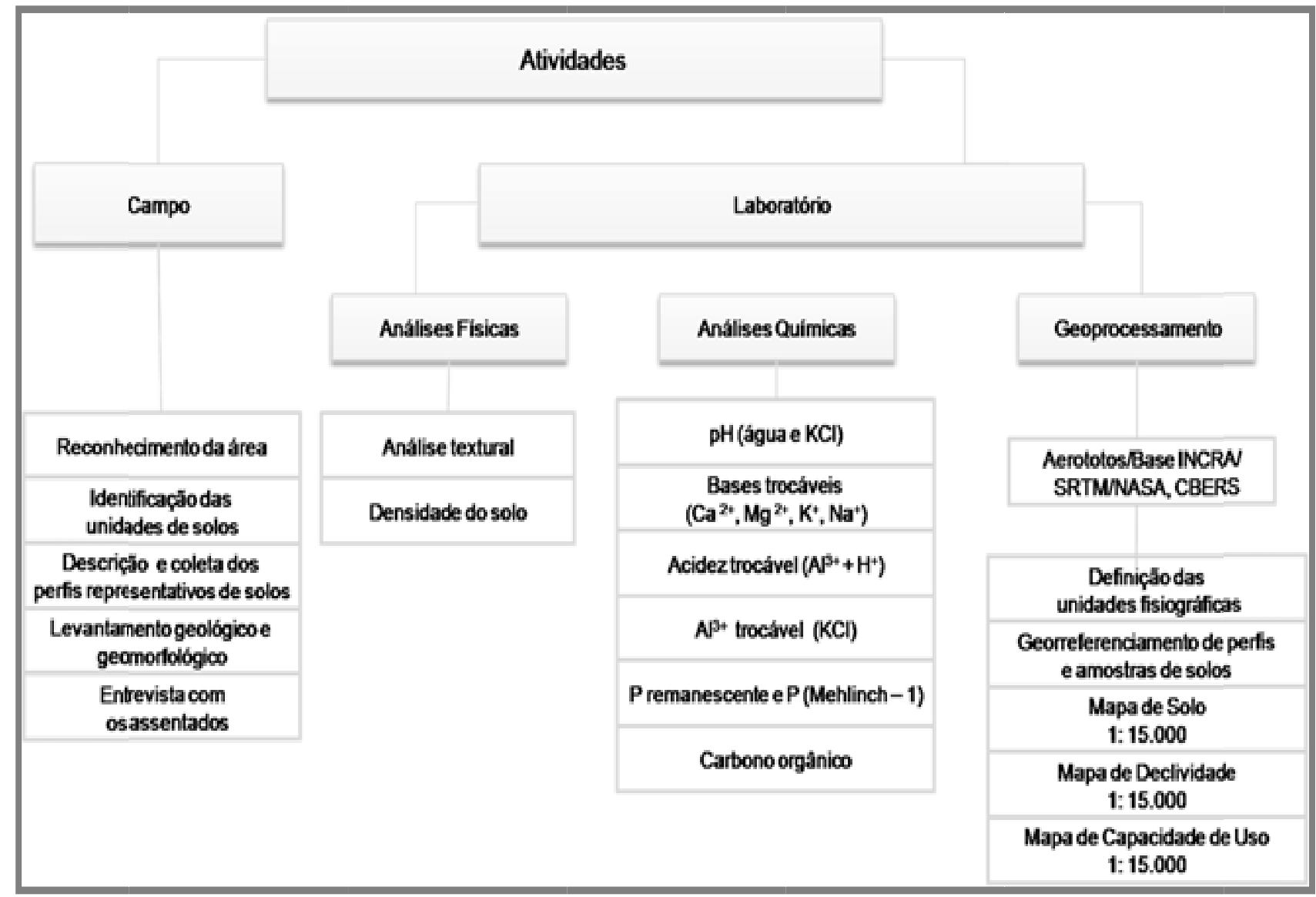

Para elaborar o mapa de relevo da área foram utilizadas imagens topográficas SRTM ( $\underline{\text { Shuttle }}$ Radar TopographyMission), que possibilita o resultado em percentagem e graus da declividade encontrada na área. Para o mapa de solos foi utilizado informações de literatura (Embrapa, 1978; Radam, 1983), imagens topográficas SRTM, mosaico de aerofotos na escala de 1:15.000, com isto foi possível gerar o mapa de unidades fisiográficas da área de estudo para determinar o processo de amostragem no campo. A partir do levantamento e classificação dos solos no campo, coleta de pontos no GPS, resultados analíticos dos solos (análises físicas e químicas) associados ao modelo pedológico e fisiográfico fez-se o cruzamento dos dados através da utilização do software de geoprocessamento Arcgis 9.3. e assim identificou as principais classes de solos segundo os critérios e definições contidos no Sistema Brasileiro de Classificação de Solos (Embrapa, 1999; 2006). A partir dos dados do levantamento e classificação dos solos foi possível obter a classificação da Capacidade de Uso da Terra conforme metodologia de Lepchet al. (1991).

No trabalho de identificação, classificação e quantificação das florestas e do uso do solo no Assentamento Che Guevara, utilizou-se a base cartográfica do INCRA, mosaico de aerofotos na escala de 1:10.000 e informações e pontos de GPS coletados no campo que foram analisadas digitalmente também pelo programa Arcgis 9.3. O mapeamento do uso do solo foi quantificado em área antrópica (capoeira, pastagem e agricultura) e não antrópica. 


\section{RESULTADOS E DISCUSSÕES}

\section{Geomorfologia}

A área do PA Ernesto Che Guevara possui sua estrutura geológica dividida entre Rochas Cristalinas PréCambrianas e manto de Sedimentos Terciários (Grupo Barreiras) e Quaternários (Aluviões e Sedimentos Marinhos). As rochas Cristalinas Pré-Cambrianas são de aspecto gnáissico em sua quase totalidade e fazem parte do Escudo Cristalino Brasileiro. Caracterizam-se por evidenciarem fáceis de metamorfismo de médio a alto grau, originadas em condições físico-químicas de meso e catazona e referidas à era Arqueozóica (EMBRAPA, 1978).Dentre as unidades do Complexo Paraíba do Sul ocorrem gnaisses (granatíferos e kinzigitos) assumindo estrutura homogênea, tomando aspectos de granadas gnaisses granitóides (EMBRAPA, 1978; RADAMBRASIL, 1983).

Geomorfologicamente encontra-se nas Faixas de dobramentos do ciclo brasiliano Atlântico em áreas de Serras e Planaltos do Atlântico leste-sudeste. O modelado dominante do planalto Atlântico é constituído por uma série de elevações, definidas como domínio dos "mares de morros". Estas são áreas com morros arredondados do tipo meia laranja, mascarando superfícies aplainadas de cimeira ou intermontanas, patamares de pedimentação e eventuais terraços. Há a presença de forte decomposição de rochas cristalinas e de processos de convexização em niveis intermontanos (AB'SABER, 2003).

O PA Ernesto Che Guevara apresenta um relevo dissecado, vales suspensos em forma de "V", convexoconvexo, predomina os trechos fortemente ondulados, com variação de altitudes entre $500 \mathrm{a} 620 \mathrm{~m}$. Esses trechos correspondem a 201,19 ha (43,38\%) da área total do assentamento (Tabela1). Outra característica do relevo no Assentamento são as vertentes muito íngremes e uma grande diferença de altitude entre o talvegue e o topo.O relevo montanhoso representa 24,76 ha $(5,34 \%)$ e são áreas acidentadas com uso restrito para agricultura, sendo mais propício para pastagens e reflorestamento. $\mathrm{O}$ relevo forte ondulado representa áreas cultiváveis com restrições e devem ser adotadas práticas intensivas de conservação do solo.

Tabela 1. Classes de relevo, declividade, características do relevo e tipo de uso do solo indicados encontradas no PA Ernesto Che Guevara, Mimoso do Sul, ES.

\begin{tabular}{|c|c|c|c|c|c|}
\hline \multirow{2}{*}{$\begin{array}{l}\text { Classes } \\
\text { de relevo }\end{array}$} & \multirow{2}{*}{$\begin{array}{l}\text { Classes de } \\
\text { declividade } \\
--\% \text {--- }\end{array}$} & \multicolumn{2}{|l|}{ Área } & \multirow[t]{2}{*}{ Características } & \multirow{2}{*}{$\begin{array}{l}\text { Tipo de uso do solo } \\
\text { indicados }\end{array}$} \\
\hline & & ha & $\%$ & & \\
\hline Plano & $0-3$ & 16,88 & 3,64 & $\begin{array}{l}\text { Superfície de topografia plana, } \\
\text { onde os desnivelamentos são } \\
\text { muito pequenos. }\end{array}$ & $\begin{array}{l}\text { Agricultura intensa, } \\
\text { sem restrições. }\end{array}$ \\
\hline $\begin{array}{c}\text { Suave } \\
\text { Ondulado }\end{array}$ & $3-8$ & 44,18 & 9,52 & $\begin{array}{l}\text { Superfície de topografia pouco } \\
\text { movimentada, declives suaves. }\end{array}$ & $\begin{array}{l}\text { Agricultura com } \\
\text { práticas moderadas } \\
\text { conservacionistas. }\end{array}$ \\
\hline Ondulado & $8-20$ & 176,79 & 38,12 & $\begin{array}{l}\text { Superfície pouco movimentada, } \\
\text { declive moderado. }\end{array}$ & $\begin{array}{ll}\text { Agricultura } & \text { com } \\
\text { rotação, limite } & \text { do } \\
\text { trator. } & \end{array}$ \\
\hline $\begin{array}{l}\text { Forte } \\
\text { Ondulado }\end{array}$ & $20-45$ & 201,19 & 43,38 & $\begin{array}{l}\text { Superfície movimentada, } \\
\text { formada por declives fortes } \\
\text { (elevações de } 50 \text { a } 100 \mathrm{~m} \text { e de } 100 \\
\text { a } 200 \mathrm{~m} \text { de altura). }\end{array}$ & $\begin{array}{l}\text { Culturas permanentes } \\
\text { com restrições práticas } \\
\text { intensivas de } \\
\text { conservação. }\end{array}$ \\
\hline Montanhoso & $>45$ & 24,76 & 5,34 & $\begin{array}{l}\text { Superfície de topografia } \\
\text { acidentada, predomínio de formas } \\
\text { acidentadas, usualmente } \\
\text { constituídas por morros, maciços } \\
\text { montanhosos, apresentando } \\
\text { relativamente grandes e declives } \\
\text { fortes e muito fortes. }\end{array}$ & $\begin{array}{l}\text { Área de preservação } \\
\text { permanente ou culturas } \\
\text { permanentes com } \\
\text { práticas intensivas de } \\
\text { conservação do solo. }\end{array}$ \\
\hline Total & & 3,79 & & & \\
\hline
\end{tabular}


O relevo ondulado (8 a 20\% de declividade), com 176,79 ha $(38,12 \%)$ da área,caracterizase por superfície pouco movimentada e declive moderado e devem ser utilizados com práticas intensivasde conservação do solo. Já as áreas planas e suavemente onduladas com variação de declividade de 0 a $8 \%$, representam 61,08 ha $(13,16 \%)$ da área total. Estas áreas apresentam melhor aptidão para agricultura intensiva e não apresentam restrição quanto ao uso de práticas agrícolas. Deve-se ter cuidado com as áreas próximas aos corpos hídricos, destinadas por lei à preservação.

\section{Solos}

Predomina no PA Ernesto Che Guevara o Latossolo Vermelho-Amarelo (LVA) com uma área de 345,52 ha $(74,5 \%)$, localizam no terço superior e médio da paisagem, relevo forte ondulado a montanhoso intensamente dissecado, com topos arredondados (meia laranja), pedoforma convexo-convexa. Nas encostas mais íngremes se associam ao CambissoloLatossólico (CX2) que representa cerca de 14,48 ha $(3,1 \%)$ da área total do Assentamento. Nos topos e no terço superior ocorrem também os Afloramentos de Rochas e o CambissoloHáplico (CX) que representam 59,77 ha (12,9\%). O Argissolo Vermelho-Amarelo(PVA) ocorre no terço inferior e nos terraços, pedoforma côncavo-côncava, constituído por elevações de topos angulares e vertentes planas com 26,20 ha $(5,6 \%)$. No fundo do vale, nas planícies fluviais, ocorre o GleissoloHáplico(GX) com 17,77 ha $(3,9 \%)$.

No PA Ernesto Che Guevara, os perfis Latossolo Vermelho-Amarelo, apresentam textura mais arenosa na parte superficial em razão da intensa erosão laminar que carrega as partes mais finas (argila) e concentra as mais grosseiras (areia grossa) (Tabela 2). Geralmente, são muito porosos (chegando às vezes a ter $70 \%$ de poros), pouco coesos, de alta friabilidade e permeabilidade. A drenagem é acentuadamente a moderadamente drenados e as estruturas são predominantemente blocos subangulares fracos que se desfazem em grânulos. Já os Argissolos apresentaram textura arenosa e média nos horizontes superficiais e nos horizontes subsuperficiais textura argilosa. A drenagem é variável podendo ser forte a moderadamente drenados, a profundidade é variável. A consistência é friável quando o solo está úmido não plástico e ligeiramente plástico a pegajoso quando molhado, principalmente, nos perfis de textura argilosa. A estrutura é predominantemente fraca ou moderada, pequena, média e grande granular ou grãos simples no horizonte A e pequena e média em blocos subangulares no horizonte Bt (EMBRAPA, 2006). Esses solos com Bt ocorrem principalmente no terço inferior das encostas, onde a atuação do processo erosivo tende a ser mais intensa, gerando solos mais rasos e menos floculados, levando a perda dessa argila para o horizonte B por elutriação ou acumulação. Devido a susceptibilidade a erosão, é mais susceptível a ocorrência de ciclos de umedecimento e secagem e a formação de estruturas em blocos, o que facilitam a perda da argila na superfície e consequentemente uma pronunciada erosão laminar. 
Tabela 2. Características fisicas das amostras de solos do PA Ernesto Che Guevara, Mimoso do Sul, ES.

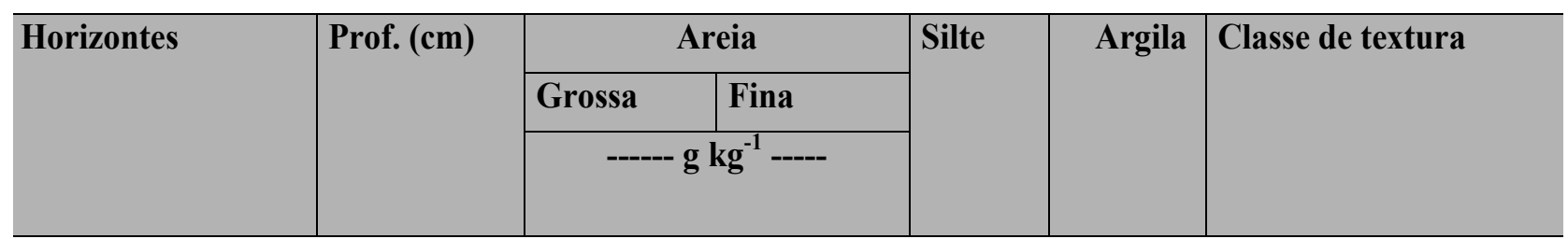

Latossolo Vermelho-Amarelo distrófico A moderado textura argilosa fase Floresta subperenifólia relevo montanhoso a forte ondulado

\begin{tabular}{l|l|l|l|l|l|l}
\hline $\mathrm{Ap}$ & $0-20$ & 420 & 150 & 130 & 300 & Franco argilo argilosa \\
\hline $\mathrm{Bw}$ & 100 & 310 & 110 & 170 & 410 & Argila \\
\hline
\end{tabular}

Latossolo Vermelho Amarelo distrófico A moderado textura argilosa fase Floresta subperenifólia relevo montanhoso a forte ondulado

\begin{tabular}{|c|c|c|c|c|c|c|}
\hline Ap & $0-20$ & 600 & 190 & 100 & 110 & Areia franca \\
\hline \multicolumn{7}{|c|}{$\begin{array}{l}\text { Argissolo Vermelho-Amarelo distrófico típico A moderado textura média fase Floresta subperenifólia relevo } \\
\text { montanhoso a forte ondulado }\end{array}$} \\
\hline$\overline{A p}$ & $0-20$ & 510 & 170 & 160 & 160 & Franco argilosa \\
\hline$\overline{\mathrm{Bt}}$ & 100 & 320 & 210 & 160 & 310 & Franco argilo argilosa \\
\hline
\end{tabular}

Argissolo Vermelho-Amarelo distrófico típico A moderado textura argilosa fase Floresta subperenifólia relevo montanhoso a forte ondulado

\begin{tabular}{l|l|l|l|l|l|l}
\hline $\mathrm{Ap}$ & $0-20$ & 710 & 130 & 50 & 110 & Areia franca \\
\hline $\mathrm{Bt}$ & 100 & 300 & 170 & 70 & 460 & Argilo argilosa \\
\hline
\end{tabular}

Argissolo Vermelho-Amarelo eutrófico A moderado textura argilosa fase Floresta subperenifólia relevo montanhoso a forte ondulado

\begin{tabular}{l|l|l|l|l|l|l}
\hline $\mathrm{Ap}$ & $0-20$ & 500 & 200 & 160 & 140 & Franco argilosa \\
\hline $\mathrm{Bt}$ & 100 & 240 & 180 & 170 & 410 & Argila \\
\hline
\end{tabular}

Argissolo Vermelho-Amarelo distrófico A moderado textura argilosa fase Floresta subperenifólia relevo ondulado (sopé da encosta)

\begin{tabular}{l|l|l|l|l|l|l|}
\hline Ap & $0-20$ & 530 & 140 & 160 & 170 & Franco argilosa \\
\hline
\end{tabular}

CambissoloHáplico Tb eutrófico A moderado textura argilosa fase Floresta subperenifólia relevo montanhoso forte ondulado

\begin{tabular}{l|l|l|l|l|l|l}
\hline Ap & $0-20$ & 620 & 160 & 140 & 80 & Areia franca \\
\hline
\end{tabular}

CambissoloHáplico Tb eutrófico A moderado textura argilosa fase Floresta subperenifólia relevo montanhoso a forte ondulado

\begin{tabular}{l|l|l|l|l|l|l}
\hline $\mathrm{A}$ & $0-20$ & 740 & 130 & 100 & 30 & Areia \\
\hline $\mathrm{B} 1$ & 100 & 440 & 140 & 220 & 200 & Franco argilosa \\
\hline $\mathrm{C}$ & 200 & 440 & 270 & 190 & 100 & Franco argilosa \\
\hline $\mathrm{Cr}$ & 400 & 660 & 220 & 140 & 80 & Areia franca \\
\hline (Rocha-Feldspato) & 500 & 620 & 230 & 100 & 50 & Areia \\
\hline
\end{tabular}

GleissoloHáplico Tb distrófico relevo plano

\begin{tabular}{l|l|l|l|l|l|l}
\hline A & 10 & 410 & 340 & 160 & 90 & Areia franca
\end{tabular}


As frações granulométricas mais grosseiras (areia) são constituídas principalmente por quartzo, têm reduzida capacidade de reter a água e a baixa adsorção de nutrientes. No perfil de Cambissolo Háplico predomina no horizonte superficial a textura arenosa. Apresenta o horizonte $\mathrm{B}$ incipiente menos estruturado com textura média. Definidos pela posição na paisagem acabam por tornar este ambiente ainda mais susceptível ao dissecamento, o que é evidenciado pela forte presença de ravinas. Estes ambientes são instáveis, de grande lixiviação e remoção de nutrientes.

As propriedades morfológicas dos Gleissolos na área de estudo revelaram a predominância de coloração acinzentada escura no horizonte superficial, com textura areia franca. A estrutura é maciça e consistência friável quando úmido e não plástico e não pegajoso quando molhado. Estes solos possuem uma variedade textural o que influencia no manejo e uso da terra.

A textura relaciona-se, direta ou indiretamente, com muitas propriedades químicas e físicas do solo, como a capacidade de troca de cátions (CTC), a retenção e infiltração de água, a drenagem, a erodibilidade dentre outras (STRECK et al., 2003). A fração argila influi acentuadamente em propriedades e características do solo por apresentar grande área superficial específica e elevada densidade de carga, o que resulta na alta reatividade química desta fração. A textura é um dos mais importantes controladores da erosão devido à estreita relação com as propriedades de coesão do solo, estabilidade dos agregados, assim como a permeabilidade. O domínio das frações areia fina e silte, por exemplo, favorecem maior erodibilidade. De modo geral, os solos que apresentam percentuais elevados de argila possuem boa coesão e estabilidade estrutural (MAFRA, 2007).

Quanto à fertilidade, os perfis de solos estudados apresentam baixos teores de bases trocáveis, embora, nos horizontes superficiais os teores sejam maiores conforme Tabela 3. Dentre os aspectos adversos ligados à baixa fertilidade dos solos são: a alta acidez (toxidez por Al), baixas reservas de K, alta capacidade de fixação de P. A produção e a produtividade das culturas são dependentes de muitos atributos de solo, de planta, de sistemas de manejo e de clima que afetam, direta ou indiretamente, o crescimento dos vegetais (WOOD et al. 2004).

No perfil 1, Latossolo Vermelho-Amarelo, o valor da soma de bases (SB) foi baixo no horizonte A com 1,25 $\mathrm{cmol}_{\mathrm{c}} \mathrm{kg}^{-1}$ e no horizonte B, 0,77 $\mathrm{cmol} \mathrm{kg}_{\mathrm{c}}^{-1}$. Nos perfis 2, 3 e 4, Argissolos Vermelho-Amarelos, os valores variaram no horizonte A de 1,83 a $3,31 \mathrm{cmol}_{\mathrm{c}} \mathrm{kg}^{-1}$, classificados como teores médios para as plantas (CFSEMG, 1999). Já nos horizontes Bt, os valores foram de 1,02 a 2,52 $\mathrm{cmol}_{\mathrm{cg}} \mathrm{kg}^{-1}$, classificados como baixos a médios teores para as plantas. No perfil 5, Cambissolo Háplico, os valores foram de $2,47 \mathrm{cmol}_{\mathrm{c}} \mathrm{kg}^{-1}$ no horizonte $\mathrm{A} ; 2,36 \mathrm{cmol} \mathrm{kg}_{\mathrm{c}} \mathrm{kg}^{-1}$ no horizonte B e 4,63 $\mathrm{cmol}_{\mathrm{c}} \mathrm{kg}^{-1}$ no horizonte C. O valor de SB no perfil 6, Gleissolo Háplico, foi de $0,87 \mathrm{cmol}_{\mathrm{c}} \mathrm{kg}^{-1}$.

$\mathrm{O} \mathrm{pH}\left(\mathrm{H}_{2} \mathrm{O}\right)$ dos perfis de Argissolos Vermelho-Amarelos apresentaram valores entre 5,1 e 6,2; Latossolo Vermelho-Amarelo, 5,1 e 5,2 e no CambissoloHáplico5,8 e 5,9 sendo considerados solos ácidos a moderadamente ácido. Os valores baixos de $\mathrm{pH}$ podem ocorrer danos ao crescimento em razão de elevadas concentrações de elementos potencialmente tóxicos, como Al, além de afetar a disponibilidade dos nutrientes para as plantas. No Perfil 4, o elevado valor de $\mathrm{pH}(6,2)$ favorecem a disponibilidade de cátions trocáveis, tendo correlação direta com os valores de $\mathrm{V}$ e CTC. Consequentemente, o teor de $\mathrm{Al}^{3+}$ trocável e os valores de saturação por alumínio são nulos. 
Tabela 3. Características químicas das amostras de solos do PA Che Guevara, Mimoso do Sul, ES.

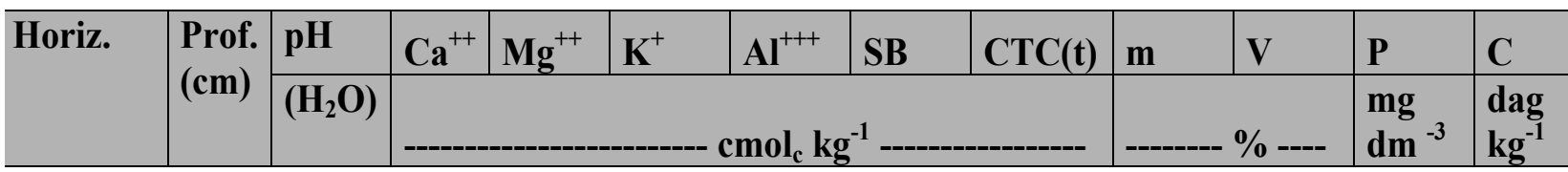

Latossolo Vermelho-Amarelo distrófico A moderado textura argilosa fase Floresta subperenifólia relevo montanhoso a forte ondulado

\begin{tabular}{l|l|l|l|l|l|l|l|l|l|l|l|l}
\hline $\mathrm{Ap}$ & $0-20$ & 5,1 & 0,7 & 0,5 & 0,51 & 0,4 & 1,25 & 1,65 & 24 & 26 & 1,2 & 1,05 \\
\hline $\mathrm{Bw}$ & 100 & 5,5 & 0,4 & 0,2 & 1,69 & 0 & 0,77 & 0,77 & 0 & 37 & 2,1 & 0,29 \\
\hline
\end{tabular}

Latossolo Vermelho Amarelo distrófico A moderado textura argilosa fase Floresta subperenifólia relevo montanhoso a forte ondulado

\begin{tabular}{l|l|l|l|l|l|l|l|l|l|l|l|l}
\hline Ap & $0-20$ & 6,2 & 2,7 & 0,6 & 0,33 & 0 & 3,63 & 3,63 & 0 & 69 & 0,6 & 1,69 \\
\hline
\end{tabular}

Argissolo Vermelho-Amarelo distrófico típico A moderado textura argilosa fase Floresta subperenifólia relevo montanhoso a forte ondulado

\begin{tabular}{l|l|l|l|l|l|l|l|l|l|l|l|l}
\hline $\mathrm{Ap}$ & $0-20$ & 5,1 & 1,2 & 0,5 & 1,3 & 0,2 & 1,83 & 2,03 & 10 & 41 & 1,2 & 1,1 \\
\hline $\mathrm{Bt}$ & 100 & 5,2 & 0,6 & 0,4 & 0,18 & 0 & 1,02 & 1,02 & 0 & 51 & 0,4 & 0,17 \\
\hline
\end{tabular}

Argissolo Vermelho-Amarelo eutrófico típico A moderado textura argilosa fase Floresta subperenifólia relevo montanhoso a forte ondulado

\begin{tabular}{l|l|l|l|l|l|l|l|l|l|l|l|l}
\hline $\mathrm{Ap}$ & $0-20$ & 5,4 & 1,2 & 0,5 & 1,48 & 0 & 1,85 & 1,85 & 0 & 44 & 1 & 1,1 \\
\hline $\mathrm{Bt}$ & 100 & 6,2 & 2,1 & 0,4 & 0,23 & 0 & 2,52 & 2,52 & 0 & 63 & 0,6 & 0,52 \\
\hline
\end{tabular}

Argissolo Vermelho-Amarelo eutrófico A moderado textura argilosa fase Floresta subperenifólia relevo montanhoso a forte ondulado

\begin{tabular}{l|l|l|l|l|l|l|l|l|l|l|l|l}
\hline $\mathrm{Ap}$ & $0-20$ & 6,1 & 1,8 & 1,2 & 3,15 & 0 & 3,31 & 3,31 & 0 & 65 & 2,7 & 1,57 \\
\hline $\mathrm{Bt}$ & 100 & 6,1 & 0,7 & 0,6 & 0,95 & 0 & 1,39 & 1,39 & 0 & 55 & 1,7 & 0,35 \\
\hline
\end{tabular}

Argissolo Vermelho-Amarelo distrófico A moderado textura argilosa fase Floresta subperenifólia relevo ondulado (sopé da encosta)

\begin{tabular}{l|l|l|l|l|l|l|l|l|l|l|l|l}
\hline Ap & $0-20$ & 4,5 & 0,4 & 0,1 & 0,74 & 1 & 0,57 & 1,57 & 64 & 12 & 1,2 & 1,28 \\
\hline
\end{tabular}

CambissoloHáplico $\mathrm{Tb}$ eutrófico A moderado textura argilosa fase Floresta subperenifólia relevo montanhoso forte ondulado

\begin{tabular}{l|l|l|l|l|l|l|l|l|l|l|l|l}
\hline Ap & $0-20$ & 5,8 & 2,8 & 0,7 & 2,35 & 0 & 3,74 & 3,74 & 0 & 67 & 1 & 1,45 \\
\hline
\end{tabular}

CambissoloHáplico $\mathrm{Tb}$ eutrófico A moderado textura argilosa fase Floresta subperenifólia relevo montanhoso a forte ondulado

\begin{tabular}{l|l|l|l|l|l|l|l|l|l|l|l|l}
\hline $\mathrm{Ap}$ & $0-20$ & 5,8 & 1,5 & 0,7 & 2,71 & 0 & 2,47 & 2,47 & 0 & 62 & 1,4 & 1,05 \\
\hline $\mathrm{B}$ & 100 & 5,8 & 1,1 & 1,2 & 0,64 & 0,5 & 2,36 & 2,86 & 17 & 67 & 0,1 & 0,06 \\
\hline $\mathrm{C}$ & 200 & 5,9 & 2,1 & 2,5 & 0,33 & 0,9 & 4,63 & 5,53 & 16 & 76 & 0,1 & 0 \\
\hline $\mathrm{Cr}$ & 400 & 5,8 & 0,5 & 0,6 & 0,59 & 0,2 & 1,16 & 1,36 & 15 & 70 & 0,8 & 0 \\
\hline $\begin{array}{l}\text { Rocha- } \\
\text { Feldspato }\end{array}$ & 500 & 5,6 & 0,4 & 0,8 & 34 & 0,87 & 1,29 & 2,79 & 54 & 53 & 0,4 & 0 \\
\hline
\end{tabular}

GleissoloHáplico $\mathrm{Tb}$ distrófico relevo plano

\begin{tabular}{l|l|l|l|l|l|l|l|l|l|l|l|l}
\hline Ap & $0-20$ & 5,5 & 0,6 & 0,2 & 27 & 0,3 & 0,87 & 0,69 & 26 & 18 & 4 & 3,14 \\
\hline
\end{tabular}


Em relação à CTC efetiva, os valores nos horizontes superficiaisdos perfis foram entre 1,65 a 3,31 $\mathrm{cmol} \mathrm{kg}_{\mathrm{c}} \mathrm{kg}^{-1}$, teores baixos a médio. Nos horizontes B, os valores variaram de muito baixos a médios, 0,77 a 2,86 $\mathrm{cmol}_{\mathrm{c}} \mathrm{kg}^{-1}$. Os teores de carbono orgânico variam de muito baixos a baixos, 0,29 a 1,05 dag $\mathrm{kg}^{-1}$. Esses valores indicam a necessidade de ser preservada a matéria orgânica por um manejo adequado do solo quando submetidos ao uso.

\section{Capacidade de uso da terra}

De acordo com a metodologia de Lepschet al (1991) de capacidade de uso, as terras do PA Che Guevara foram enquadradas nas classes de capacidade de uso III, VII e VIII conforme Tabela 4.

Tabela 4. Distribuição das classes de capacidade de uso das terras do PA Ernesto Che Guevara, município de Mimoso do Sul, ES.

\begin{tabular}{|c|c|c|c|}
\hline \multirow{2}{*}{$\begin{array}{ll}\text { Classes } & \text { de } \\
\text { capacidade } & \text { de } \\
\text { uso } & \\
\end{array}$} & \multirow[b]{2}{*}{ Descrição } & \multicolumn{2}{|c|}{ Área } \\
\hline & & ha & $\%$ \\
\hline Classe III & $\begin{array}{l}\text { Terras cultiváveis que requerem } \\
\text { medidas intensivas ou complexas para } \\
\text { utilização com culturas anuais com } \\
\text { problemas complexos de conservação do } \\
\text { solo }\end{array}$ & 393,21 & 84,8 \\
\hline Classe VII & $\begin{array}{l}\text { Terras com severas limitações, } \\
\text { cultiváveis em casos especiais com } \\
\text { culturas permanentes e adaptadas em geral } \\
\text { para pastagem ou reflorestamento. } \\
\text { Apresentam limitações, com problemas } \\
\text { complexos de conservação de solos. }\end{array}$ & 17,77 & 3,83 \\
\hline ClasseVIII & $\begin{array}{l}\text { Terras impróprias para culturas, } \\
\text { pastagens ou reflorestamento, podendo } \\
\text { servir como abrigo de fauna silvestre e, ou, } \\
\text { como ambiente para fins de } \\
\text { armazenamento de água ou recreação. }\end{array}$ & 52,77 & 11,38 \\
\hline TOTA & & 63,79 & 0,0 \\
\hline
\end{tabular}

As terras cultiváveis com medidas intensivas, Classe III, correspondem às áreas dos Latossolos Vermelho-Amarelos e Argissolos Vermelho-Amarelos com 371,72 ha (80,15\%). As áreas dos Latossolos apresentam grande importância agrícola por condições físicas favoráveis à mecanização, solo profundo, com boa infiltração de água e sem pedregosidade. Como fatores limitantes ao seu aproveitamento agrícola destacam-se: baixa fertilidade natural e susceptibilidade a erosão, principalmente a laminar. Os Argissolos possuem melhor disponibilidade de água eexisteuma necessidade de serem corrigidas as suas limitações, quanto à deficiência de nutrientes e também impedimentos a mecanização ou adoção de práticas de manejo que remova o solo ao mínimo possível, a fim de evitar o adensamento ou compactação da camada superficial, que favorecida pela diferença de textura entre esta e a subsuperficial, acarretará o arraste das primeiras camadas do solo que são mais argilosas, perdendo-se a matéria orgânica e os 
nutrientes essenciais às plantas (LOPES et al.,1999).

Na Classe III foi incluído o Cambissolo Háplico com 21,49 ha (4,63\%) por apresentarem alto potencial de fertilidade devido à presença da rocha próxima a superfície, mas devido a sua pouca profundidade apresenta problemas de disponibilidade hídrica. Recomenda-se para o assentamento a sua utilização com cultivos anuais de ciclo curto e que se aproveite o período das chuvas.

A Classe VII, inclui o Gleissolo Háplico com uma área aproximada de 17,77 ha (5,83\%). Apresenta como limitações o excesso de umidade como também risco de assoreamento. São solos permanentes ou periodicamente saturados com água, salvo se artificialmente drenados, caracterizam-se pela forte gleização, resultante da ação do regime de umidade redutor, que se processa em meio anaeróbio, devido ao encharcamento do solo por longo tempo ou durante todo o ano. São formados de materiais estratificados ou não sujeitos a períodos de excesso de água. Desenvolvendo-se de sedimentos recentes nas proximidades dos cursos d'água e em materiais coluvio-aluviais sujeitos a condições de hidromorfismo. No entanto, as características dos Gleissolos estão intimamente relacionadas com as composições químicas e mineralógicas dos sedimentos que lhes deram origem. Por isso, podem apresentar-se eutróficos ou distróficos, com argila de atividade alta ou baixa, como também, com diferentes condições de hidromorfismo, de acordo com a dinâmica do regime de inundação a que estão sujeitas as áreas de ocorrência desses solos.

Na classe VIII com 52,77 ha (11,37\%), foram incluídos o Afloramento de Rocha, Neossolos Litólicos e os Cambissolos Latossólicos, o uso dessas áreas classificada para preservação da fauna e flora (Reserva Legal). Os Neossolos Litólicos são solos pouco desenvolvidos, assentados diretamente sobre a rocha, principalmente gnaisse. Ocorrem em áreas de relevo montanhoso e escarpado, onde a erosão hídrica foi normalmente mais ativa durante a gênese destes solos. São solos de fertilidade natural variada e, por serem rasos e poucos intemperizados, conservam afinidade com o material de origem. A pequena espessura destes solos é talvez, um dos maiores obstáculos ao seu aproveitamento agrícola, principalmente quando associada ao relevo mais movimentado, agravando mais ainda a situação de disponibilidade hídrica e da própria sustentação de plantas mais altas.

Os Cambissolos Latossólicos caracterizam-se por serem solos rasos, declivosos e apresentam grande potencial de deslizamento e de erosão, iniciando neles as voçorocas. Os conteúdos da fração areia são mais altos do que os das frações argila e silte, podendo eventualmente facilitar o processo de erosão pela perda das camadas superficiais, devido ao baixo conteúdo da fração argila total, que é insuficiente para formar agregados estáveis no solo (EMBRAPA, 2006).

\section{Avaliação do uso da terra}

No PAChe Guevara, as áreas antrópicas representam 382,21 ha (82,40\%) do total da área, considerando áreas de capoeira, pastagem e agricultura de subsistência. A área total de Floresta em estágio secundário de regeneração é de 81,60 ha $(17,60 \%)$.

A região onde se encontra o PA Che Guevara, faz parte do conceito ecológico da Floresta Estacional Semidecidual proposto por Veloso e Góes-Filho(1982). Dentro desse conceito faz parte das Formações de Florestas Submontanas, com relevo dissecado típico, situando-se entre as altitudes de 50 e $500 \mathrm{~m}$ (RADAMBRASIL, 1983). Esse tipo de formação apresenta como espécies mais frequentes do estrato dominante canelas (Ocoteasp. e Nectandra sp.), araribá (Centrolobium sp.), braúna (Melanoxylon sp.), cabiúna (Dalbergia sp.), cedro (Cedrela sp.), ipê (Tecoma sp.), peroba-do-campo (Paratecoma sp.), Erythrina, Tabebuia e Cariniana (RADAMBRASIL, 1983).

A Reserva Legal deveria representar um mínimo de $20 \%$ da área total da propriedade do Assentamento, mas através dos dados do INCRA (2008), verificou-se que as áreas delimitadas como reserva legal não 
eram suficientes para atingir os $20 \%$ exigidos pela legislação, pois somava 14,6\%, tornando-se necessária a inclusão de novas áreas como reserva. Dessa forma, como uma proposta, incluiu-se como Área de Reserva Legal aproximadamente 25 ha (5,4\%), com a finalidade de complementar os $20 \%$ necessários. Para a escolha das áreas utilizou-se de critérios ecológicos na criação de corredores entre fragmentos de floresta nativa. Algumas áreas de capoeira nas bordas dos fragmentos também foram inclusas na proposta de reserva. As áreas de capoeira são estratégicas para a complementação da área necessária de Reserva Legal, pois apresentam em processo de regeneração natural, podem em pouco tempo formar uma vegetação florestal secundária, com maior diversidade de espécies.

Foram definidas como APP, as áreas dentro de um raio de 50 metros de largura em relação às nascentes; áreas definidas a 30 metros de ambos os lados dos cursos d'água; terço superior dos topos de morros quando não coincidente com as áreas de Reserva Legal previamente definidas; e áreas com declividade superior a $45 \%$.

No caso do Assentamento Che Guevara, as áreas de APP mensuradas representam 27,03\% da área total, que somados aos $20 \%$ necessários para a reserva legal, representam $47,03 \%$ da área total do Assentamento. Entretanto, o IEMA juntamente com o INCRA têm discutido esses casos, com a finalidade de otimizar e não limitar o uso dentro dos lotes.

O sistema produtivo do PA Che Guevara ainda é incipiente, pois esta em fase de implantação das culturas agrícolas, por este motivo, ainda predomina a produção para a subsistência das famílias. As culturas mais importantes em área plantada são café, milho, feijão e a banana. É importante considerar que as áreas de cultivo no assentamento são utilizadas frequentemente de modo consorciado, isto é uma mesma área produtiva é utilizada para o plantio de diversas culturas agrícolas. Assim é comum o plantio do café consorciado com as culturas de banana, milho, feijão, hortaliças, frutíferas, árvores fontes de madeiras, dentre outros, diversificando as áreas produtivas com culturas comerciais associadas a culturas voltadas para a subsistência.

Desta maneira, conforme visto acima, o PA Ernesto Che Guevara possui 84,8\% das terras pertenceà Classe III que são terras cultiváveis com problemas relativos ao solo e susceptibilidade à erosão e requerem medidas de intensivas de conservação para utilização. Nesta área da Classe III, 287,7 ha $(73,2 \%)$ estão sendo utilizadas, de forma adequada, com uso de pastagem e agricultura com culturas anuais e perenes seguindo o modelo de capacidade de uso da terra, principalmente, o café conilon, a banana e o milho voltados para subsistência. Cerca de 105,8 $(26,8 \%)$ da área com aptidão para lavoura estão sendo utilizadas como floresta e capoeira.

As terras pertencentes a Classe VII passíveis para pastagens ou reflorestamento com problemas complexos de conservaçãoe limitações relativas ao solo e excesso de água corresponde 3,83\% da área do assentamento.O uso atual nestas áreas é de 12,5 ha $(72,62 \%)$ com pastagem e agricultura e 4,7 ha $(27,32 \%)$ áreas de capoeira e floresta.

As terras não adequadas para cultivos anuais, perenes, pastagens ou reflorestamento, com aptidão para proteção da flora e fauna silvestre, recreação ou armazenamento de água corresponde a Classe VIII que representa52,77 ha (11,38\%) do assentamento. Cerca de 16,4 ha (31\%) destas terras estão sendo subutilizadas com uso de pastagem e agricultura associado ao manejo inadequado. A falta de medidas de conservação dos solos associado com construção de estradas e casas tem gerado inúmeros processos erosivos que foram identificados na área. Estas causas associadas à forma de relevo com declive acentuado e as classes de solo, principalmente o Cambissolo Latossólico tornam a área totalmente suscetível à erosão. 
Tabela 5. Capacidade de uso e uso atual do solo do PA Ernesto Che Guevara, Mimoso do Sul, ES.

\begin{tabular}{lllllll}
\hline \multirow{2}{*}{ Uso do solo } & VIII & \multicolumn{3}{c}{ III e,s } & \multicolumn{3}{c}{ VII s,a } \\
\cline { 2 - 7 } & ha & $\%$ & Há & $\%$ & ha & $\%$ \\
\hline Pastagem & 15,2 & 28,8 & 268,2 & 68,2 & 12,3 & 71,57 \\
Capoeira & 7,5 & 14,2 & 55,7 & 14,1 & 2,5 & 14,36 \\
Floresta & 29,0 & 54,9 & 50,1 & 12,7 & 2,2 & 12,96 \\
Agricultura & 1,2 & 2,2 & 19,5 & 5,0 & 0,2 & 1,11 \\
\hline TOTAL & $\mathbf{5 2 , 8}$ & & $\mathbf{3 9 3 , 5}$ & & $\mathbf{1 7 , 1}$ & \\
\hline
\end{tabular}

Pelo observado no trabalho de campo, o plantio foi feito de forma inadequada, principalmente nos cafezais que foram locados erradamente. Não foi observado nenhum plano de aptidão agrícola, práticas de conservação e uso dos solos, nem mesmo sistema de plantio em nível. Em algumas lavouras de café visitadas percebeu-se que as mesmas foram plantadas transversalmente ao declive do terreno o que dificulta práticas de conservação de solos (cordões em contorno, terraço de base estreita, faixa de vegetação etc.) e isto está desencadeando vários processos erosivos. É importante ressaltar que a marcação da lavoura foi feita pelos próprios assentados sem orientação ou técnicas agrícolas adequadas conforme relatado nas entrevistas realizadas com os assentados.

Atualmente a degradação dos solos pode ser considerada como um dos maiores problemas ambientais que existe dentro do PA Che Guevara afetando tanto as terras agrícolas como as áreas com vegetação natural. A aceleração dos processos erosivos decorre muito mais da interferência do homem no meio ambiente do que propriamente de um evento geológico. A retirada da cobertura vegetal, construção de estradas e moradias e a agricultura não planejada são exemplos de ações do homem que rompem o equilíbrio ambiental (BERTONI, 1993).

Os fatores controladores da erosão são aqueles que determinam as variações nas taxas de erosão (erosividade da chuva, erodibilidade do solo, cobertura vegetal e topografia do terreno). É por causa da interação desses fatores que certas áreas erodem mais que as outras e a intervenção do homem pode alterar esses fatores e, consequentemente, acelerar ou retardar os processos erosivos(GUERRA, 2001).

A intensidade com que a erosão se desenvolve depende dos fatores que afetam a ruptura dos agregados que podem ser associados a algumas características morfológicas dos solos, como a textura, estrutura e o teor de matéria orgânica. Além de características do relevo, cobertura vegetal, erodibilidade da chuva e o uso e manejo do solo. Apesar de todos esses fatores interferirem sobre os agregados, a maioria dos estudos sobre erodibilidade têm indicado que, à medida que o teor de matéria orgânica diminui, aumenta a instabilidade dos agregados (GUERRA, 2008).

\section{CONSIDERAÇÕES FINAIS}

O PA Ernesto Che Guevara possui áreasutilizadas para agricultura e pastagem de forma inadequada, não respeitando a capacidade de uso destas terras já que possuem

problemas complexos de conservação e limitações relativas ao solo (pouca profundidade, baixa fertilidade) e susceptibilidade a erosão (declive acentuado) associado ao manejo inadequado está provocando vários processos erosivos. Um manejo adequado seria necessário para conservação dos solos 
e da água e com isto aumentar a sustentabilidade principalmente produtiva no Assentamento.

O desafio é compreender os processos responsáveis pela erosão, reconhecendo-os como um problema ambiental, mas, sobretudo um problema socioeconômico. Um manejo adequado e adoção de política de preservação seriam necessários para conservação dos solos e da água e com isto aumentar a sustentabilidade, principalmenteprodutiva no PA Che Guevara. Outro ponto importante é compatibilizar o uso com as limitações particulares a cada tipo de solos e aos ambientes que faz parte, criando assim uma sustentabilidade ambiental e econômica do assentamento respeitando a aptidão agrícola das terrasfundamentais para a perenidade do projeto.

\section{REFERÊNCIAS}

AB'SABER, A.N. Os Domínios de Natureza no Brasil: potencialidades paisagísticas. São Paulo: Ateliê Editorial, 2003, 142 p.

BERTONI, J.;LOMBARDI NETO, F. Conservação do solo. São Paulo: Ícone, 1993, 355p.

CFSEMG - Comissão de Fertilidade do Solo do Estado de Minas Gerais. Recomendações para uso de corretivos e fertilizantes em Minas Gerais: 5a aproximação. Viçosa 1999. 360p.

DEFELIPPO, B. V; RIBEIRO, A. C. Análise química do solo. 2. ed. Viçosa, MG: UFV, 1997. 26 p. (Boletim de extensão, 29).

EMPRESA BRASILEIRA DE PESQUISA AGROPECUÁRIA (EMBRAPA). Serviço Nacional de Levantamento e Conservação de Solos.Levantamento de reconhecimento de solos do Estado do Espírito Santo. Rio de Janeiro: 1978,461p.

EMPRESA BRASILEIRA DE PESQUISAAGROPECUÁRIA(EMBRAPA). Centro Nacional de Pesquisa de Solos. Sistema Brasileiro de Classificação de Solos. Brasília: Embrapa Produção de Informação; Rio de Janeiro: Embrapa Solos, 2006, 306p.

GUERRA, A. J. T. Processos Erosivos nas Encostas. In: CUNHA, S.B.; GUERRA, A. J. T. (orgs.). Geomorfologia: uma Atualização de Bases e Conceitos.4.ed. Rio de Janeiro: Bertrand Brasil, 2001. p. 149-209.

GUERRA, A.J.T. Encostas e a questão ambiental. In: CUNHA, S.B. e GUERRA, A.J.T. (orgs.). A questão ambiental: diferentes abordagens.4.ed. Rio de Janeiro, Editora Bertrand Brasil, 2008. p. 191-218.

INCRA. Projeto de Assentamento dirigido CONAMA (Conselho Nacional do Meio Ambiente), 1986, № 289, de 25 de outubro de 2001. Diário Oficial da União, Brasília.

LANI, J.L., ARAUJO. E.A, AMARAL, E.F., BARDALES, N.G.; GOMES, M.A., FIGUEREDO, N. A.Percepção ambiental e o uso dos recursos naturais em moldes sustentáveis. In: Indicadores de sustentabilidade em sistemas de produção agrícola.Belo Horizonte : EPAMIG, 2010, p. 125-142.

LEPSCH, I. F.; JR BELLINAZZI, R.; ESPINDOLA, C.R. Manual para levantamento utilitário do meio físico e classificação de terras no sistema de capacidade de uso. Sociedade Brasileira de Ciência do Solo. $4^{\mathrm{a}}$ aprox. Campinas, 1991. 175p. 
LOPES, O.M.N.; RODRIGUES, T.E.; OLIVEIRA JÚNIOR, R.C. de. Determinação de perdas de solos, água e nutrientes em Latossolo Amarelo, textura argilosa do Nordeste Paraense. Belém: Embrapa Amazônia Oriental, 1999. 36p. (Embrapa Amazônia Oriental. Boletim de Pesquisa, 19).

MAFRA, N.M.C. Erosão e planificação de uso do solo. In: GUERRA, A.J.T. Erosão e Conservação dos Solos. .Rio de Janeiro, Bertrand Brasil, 2007, 340p.

STRECK, E.V.; COGO, N.P. Reconsolidation of the soil surfasse after tillage discontinuity, with and without cultivation, related to erosion and its prediction with Rusle. .RevistaBrasiliera de Ciência do Solo, v. 27, p. 141-152, 2003.

RADAMBRASIL - PROJETO RADAMBRASIL.Levantamento de recursos naturais - folha SF. 23/24. Rio de Janeiro, 1983. 780p.

VELOSO, H.P.; GÓES-FILHO, L. Fitogeografia brasileira: classificação fisionômico-ecológica da vegetação Neotropical. Boletim Técnico do Projeto RADAMBRASIL. 1982. 86p. (Série Vegetação).

WOOD, B. W.; REILLY, C. C.; NYCZEPIR, A. P. Mouse-earofpecan: II. Influence of nutrient applications. Hortscience, v. 39, n. 1, p. 95 - 100, 2004

WOLSTEIN, A.R.P; LIMA, E.M; AMARAL, E.F.DO; BRAZ, E.M;PINHEIRO, F.L.N. Metodologia para o planejamento, implementação e monitoramento de projetos de assentamentos sustentáveis na Amazônia. Rio Branco: Embrapa-CPAF/AC/Incra/Funtac, 1998, 29p. 